\title{
JOSÉ PAULO PAES: A ÉTICA DO MÍNIMO
}

Maurício Guilherme Silva Júnior*

RESUMO:

0 referido ensaio pretende discutir as principais características da poesia e da obra intelectual de José Paulo Paes, assim como contextualizar o legado do autor no panorama da literatura brasileira e promover a análise crítica de seu livro póstumo, Socráticas - poemas.

PALAVRAS-CHAVE: chiste, ironia, geração de 45, epigrama, Sócrates.

Filho do caixeiro-viajante Paulo Artur Paes da Silva, português de nascença, e da paulista Diva Guimarães, o poeta, tradutor e ensaísta José Paulo Paes vem ao mundo, em 1926, já bastante próximo dos livros. Na casa onde nasceu, em Taquaritinga, interior de São Paulo, funcionava a sede da livraria do avô materno, J.V.Guimarães. É na terra natal que o escritor realiza os primeiros estudos para, em Araçatuba, no noroeste do estado, concluir o secundário. Pela primeira vez distante dos pais, em 1944, aos 18 anos, o jovem Paes transfere-se para Curitiba, onde ingressa no curso técnico de Química Industrial.

Muito além das práticas químicas, o jovem literato encontra, na efervescente Curitiba dos anos 40 , os estímulos necessários à descoberta de sua futura vocação. Na capital paranaense, além de publicar textos e poemas nas principais revistas surgidas à época, Paes realiza sua estréia literária. No ano de 1947, sai a "modesta edição doméstica" de "0 aluno", livro em cujos versos a influência modernista revela-se claramente visivel. Nos nove poemas da obra - entre os quais um "Drummondiana" e um "Muriliana" -, o autor se apresenta, como the atenta o próprio Carlos Drummond de Andrade, em carta de 25 de maio daquele ano, um "poeta que ainda não chegara a escrever os próprios poemas."(Andrade, 1997, 35)

* Mestre em Letras: Poéticas da Modernidade (Área de concentração: Literatura Brasileira), 2004. 


\section{EMTESE}

Belo Horizonte, v. 9, p. I-28I, dez. 2005

Tal conselho do mestre mineiro é tomado como alerta por José Paulo Paes, que a partir daquele momento centra forças na busca de voz e passos literários próprios. 0 que não quer dizer que o legado modernista tenha sido por ele abandonado. Ao contrário, os preceitos do Modernismo vão the servir de bússola permanente em sua jornada pelo oceano da literatura. Que o diga a máxima do crítico Fernando Paixão, para quem o poeta pode ser considerado "o último dos modernistas". (Paixão, 1999: 50-53)

Ao longo de sua trajetória poética, de "0 aluno" (1947) ao póstumo "Socráticas - poemas", publicado em 2001, José Paulo Paes, "aprendiz de modernismo", acaba por transfigurar-se em múltiplos. A dedicação à permanente pesquisa estética faz com que se torne, em linhas gerais, o poeta capaz de, a partir da herança modernista, negar o formalismo da denominada "Geração de 45" - à qual estaria ligado cronologicamente -, aproximar-se de vanguardas como a poesia Concreta, e, simultaneamente, partir em busca da construção de linguagem breve e pessoal, caracterizada por concentrar na estrutura poética apenas o que há de mais essencial.

Ao longo de seus 72 anos de vida, o poeta, tradutor e ensaísta José Paulo Paes tornou-se conhecido no universo da cultura brasileira pela vasta amplitude de sua obra intelectual. Afora os dezessete livros de poesia, publicados de 1947 a 2001, escreveu onze obras ensaísticas, compostas de crítica literária e interpretação da realidade política e socioeconômico de sua época. Além disso, dedicou-se, com atenção especial, à literatura infanto-juvenil e ao ofício da tradução. No total, traduziu mais de cem livros, tanto de prosa quanto de poesia, escritos por autores de oito diferentes idiomas.

Pouco utilizado neste início de século 21 , o termo "pensador da cultura" seria o mais apropriado para definir José Paulo Paes no cenário intelectual brasileiro. De poética marcadamente irônica e concisa, o escritor também se revela um cidadão permanentemente atento às intenções, ações e condições do homem moderno e urbano. Como ressalta o crítico Davi Arrigucci Jr., no texto "Agora é tudo história", dedicado à obra de Paes, cada poemeto do autor paulista "traz em seus próprios fundamentos os traços típicos do epigrama e sua vocação para exprimir os traços gerais da urbanidade." (Arrigucci Jr., 1998: 30) 
Criado pelo próprio Paes, o neologismo "transleitura" resume bem tal relação do poeta - como também do ensaísta, do tradutor e do cidadão participante - com a cultura, a realidade e a arte de seu tempo. "0 prefixo trans- visa principalmente, no caso, a acentuar que a leitura de uma obra literária é um ato de imersão e de distanciamento a um só tempo. Tal duplicidade do ato de leitura responde, simetricamente, à duplicidade do ato de criação literária" (Paes, 1995: 5). "Transleitura" incorpora a idéia de que cada nova obra integra um complexo sistema, "formado teoricamente por todas as obras literárias jamais escritas e por todas as interpretações ou comentários críticos que vêm suscitando."

Ao longo de sua vida, o poeta dedica-se, exatamente, ao ofício da "transleitura" do universo dos homens e das letras. A análise de seu livro póstumo, "Socráticas - poemas", que concentra boa parte das características literárias e intelectuais do autor, é possível compreender o pensamento socrático de Paes que, como o filósofo grego, preocupou-se, permanentemente, com a essência das virtudes morais e políticas. Para o poeta está na força da poesia, como também na capacidade de reflexão do indivíduo, o único meio de se encontrar a verdade. Seu livro derradeiro é, pois, o eloqüente depoimento de um homem que, em momento nenhum, temeu a presença da Morte, essa "esquina ainda por virar quando já estava quase esquecido o gosto de virá-1as." (Paes, 1998: 185)

Como revela "Socráticas", "reler" e interpretar poeticamente o mundo dos homens e dos livros foi a tarefa a que se dedicou José Paulo Paes. Para tal, lançou mão, em sua poética, de recursos como o epigrama, a ironia e o chiste. Além disso, manteve-se sempre atento à possibilidade de produzir uma literatura em que pudesse concentrar o máximo no mínimo. Desde os primeiros versos, o poeta encontra na miniaturização artística das "coisas" da vida o caminho pessoal para a transmissão e interpretação de sua experiência.

Discutir a importância da concisão no fazer poético significa ter em mãos uma das principais senhas para se adentrar o universo literário de José Paulo Paes. 0 próprio autor comentava que as discussões e teorizações sobre poesia o interessavam menos, pois o que sempre o atraiu foi a concisão. Nas palavras do poeta: "Desloco o centro de atenção do verso para a palavra, 


\section{EM TESE}

Belo Horizonte, v. 9, p. I-28I, dez. 2005

numa espécie de virada intraverbal, para os 'semas', unidades elementares da palavra". (Paes, 1990: 31-34)

A partir de tal princípio, pode-se dizer que a miniaturização do mundo, ou a ordenação poética - e subjetiva - da experiência cotidiana em pequenos poemas, ilustra exatamente o perfil, avesso a excessos, do poeta - e também do cidadão - José Paulo Paes. Somado a isso, o escritor busca, incessantemente, como bem o resume Fernando Paixão, "dar formatos novos para a expressão poética, em vez de se contentar com um estilo cristalizado" (Paixão, 1999: 5053). A começar pelo resgate do epigrama, gênero clássico retomado por Paes segundo propostas - além de inteiramente pessoais - bastante modernas.

Na obra de Paes, também o chiste assume a função de condensar, unificar e metaforizar o mundo. Como expurgador de excessos, o chiste desempenha papel importante na obra do poeta. Ele se utiliza do recurso ao longo de toda a trajetória literária, sempre ciente de suas múltiplas possibilidades. $\mathrm{Na}$ opinião de Alfredo Bosi, para José Paulo Paes o chiste funciona como recurso capaz de

encurtar as distâncias, de trazer para perto o universo longínquo, tornandoo acessível à perspectiva diminuída do mundo pequeno, familiar e íntimo, ao mesmo tempo que dá corpo concreto na brevidade à ampliação da consciência irônica e sua crescente percepção dos desencontros contraditórios do mundo. Entre 0 pequeno e o grande, o movimento que perfaz o enlace funda também o sentido. (Arrigucci Jr, 1998: 34)

Aos olhos de Paes, contra a realidade adversa, nada mais apropriado que 0 antídoto do humor. Ao miniaturizar cômica e poeticamente o mundo complexo que o circunda, José Paulo Paes traz para seus chistes e epigramas a dose de tragédia contida na comicidade. Neste ponto, também o recurso da ironia aparece como instrumento apto a catalisar e satirizar, no espaço do poema, as tensões do mundo dos homens.

A comicidade e a ironia da poesia de Paes buscam, justamente, criticar o imediatismo de uma sociedade imersa em interesses financistas e calcada, muitas vezes, em valores pouco solidários. Os ideais do poeta reforçam-se através de sua verve satírica, quando, em cada pequeno chiste, estimula a discussão em torno das tragicomédias humanas. Como na frase de Leon Eliachar, citada por Eduardo Meneses: "Humorismo é arte de fazer cócegas no raciocínio dos outros". (Meneses, 1974: 5-16) 
Tais características da trajetória poética de José Paulo Paes aparecem em seu livro póstumo. Estão nos 37 poemas de "Socráticas", que se divide em três partes principais (Alpha, Beta e Gamma), a maturidade técnica do escritor no manuseio do epigrama e de recursos como o chiste - que leva ao extremo o poema-piada dos modernistas -, e também certo tom memorialístico, fruto da transfiguração em versos da experiência sensível do poeta no mundo.

"Socráticas" concentra grande parte das características da literatura de Paes, com exceção das experiências concretistas, às quais o poeta se dedicara com mais força apenas nos livros "Anatomias", de 1967, e "Meia Palavra", de 1973. Bastante heterogêneos na forma - chistes e epigramas dividem espaço com uma série de versos em prosa -, os poemas da obra revelam a intensidade existencial do poeta diante da morte. Também está no livro o perfil multifacetado do escritor, cuja ética e inventividade revelaram-se não só no ofício do poeta, como também nas atividades do cidadão humanista.

Em Alpha, um Paes renovador do poema-piada dedica-se, em certos momentos, ao trocadilho sem pretensões, para, em outros, revelar ironicamente os traços da modernidade. Na parte Beta, o autor revela suas intensas memórias, assim como trata da ininterrupta ação do tempo sobre a experiência humana do viver. Por fim, Gamma, revela um escritor soturno e sereno, capaz de versos leves, mas longos e reflexivos. Nas duas partes finais do livro, aliás, José Paulo Paes entrega-se, de corpo e alma, à reconstituição - poética - de sua vivência. Lá estão os amigos, os valores, as homenagens, o corpo em definhamento, o ofício da tradução, as confissões a Deus, e, mais do que nunca, o caleidoscópio infindável de dúvidas e perguntas.

Para nós, "Socráticas" revela a imensa capacidade do poeta em dizer muito através de mínimas palavras. Autobiografia serena e bem-humorada - capaz de concentrar toda a trajetória literária e pessoal de José Paulo Paes -, o livro funciona como alerta ao homem moderno. Nele, o insiste na máxima socrática: "conhecete a ti mesmo". Diante das páginas do livro póstumo de um já experiente e vivido Paes, o leitor se vê diante do quanto é necessário despir-se de verdades absolutas. 0 recado jocoso aos que ficam, como ressalta Bosi na apresentação do livro, diz muito mais de incertezas e dúvidas da estrada do que presta esclarecimentos acerca da realidade concreta da existência. José Paulo Paes é socrático na 


\section{EMTESE}

Belo Horizonte, v. 9, p. I-28I, dez. 2005

medida em que, fundamentalmente, ressalta e revela quanto o "reencontro consigo mesmo só pode partir da consciência da própria ignorância." (Pessanha, 1996: 6)

A "doce ironia" de Paes é capaz de estimular o cidadão a rever-The as próprias pseudoverdades, frutos, por vezes, da disseminação do individualismo em detrimento da solidariedade. Não há pregação nos versos do livro. 0 que existe é ironia, esse inteligente ácido capaz de corroer máscaras e revelar dos homens a face verdadeira. Assim como fazia Sócrates, que através de diálogos buscava demolir conceitos pessoais já cristalizados, como única forma de tornar as pessoas aptas a caminharem em direção ao conhecimento de si mesmas.

No livro, está, de um lado, a irônica inquirição de Paes em relação ao injusto e complexo mundo dos homens. De outro, suas memórias subjetivas, cuja elevada carga de reflexão, melancolia e "silêncio" concede ao livro certo tom de serenidade e introspecção. Se os chistes de Alpha buscam criticar - e denunciar a desumanidade da máquina capitalista, Beta e Gamma concentram - de forma lírica as recordações e vivências musicais, religiosas, sentimentais e literárias do poeta.

Em "Socráticas", a arte poética, sem nenhum prejuízo estético, está a serviço da ética. Neste ponto, pode-se dizer, inclusive, que os poemas do livro compõem o que se pode chamar de "testamento" ético e estético do artista, cuja conduta socrática, expressa no "cultivo" da dúvida e na incessante busca de autoconhecimento, é revelada com plena intensidade. Cada verso do livro concentra em si o rico ciclo de comédias e tragédias da experiência existencial.

Socrático, José Paulo Paes instiga o leitor a desprezar verdades absolutas e acreditar na força - única - de seus passos próprios. Afinal, seria importante lembrar ao indivíduo a possibilidade que tem de livrar-se dos dogmas, e, desprovido de máscaras, vivenciar os momentos realmente importantes da caminhada. Como ressalta o poeta: "a visão da beleza / dura um só instante / inesquecível". (Paes, 2001: 47)

Neste início de milênio, a "mensagem" de "Sócraticas" permanece como convite à permanente reflexão. Em tempos de fundamentalismo exacerbado, por que não acreditar na "dúvida" como ponte para uma vida mais verdadeira, e menos superficial? 
$\mathrm{Na}$ opinião de Régis Bonvicino, Paes quis, com o livro, "recuperar - para a poesia, inclusive -, certos valores éticos" (Bonvicino, 2001). Na opinião do crítico, esta é, justamente, a inflexão que torna extremamente legível o conjunto da obra: "a cívica, de protesto contra os (des)valores atuais da sociedade." (Bonvicino, 2001)

Em "Socráticas", mais do que em outras obras de Paes, ética e estética - mundo e linguagem - aliam-se com o propósito de ressaltar a importância, para o homem, da dúvida e do niilismo. Afinal, nada é realmente absoluto. 0 "recado jocoso" de Paes "aos que ficaram"(Bosi, 2001: 13) referese, justamente, à necessidade de o indivíduo livrar-se de suas inúmeras certezas e crenças pessoais, responsáveis pelo pior dos fundamentalismos.

Em seu testamento poético, José Paulo Paes revela seu grande niilismo. Mesmo próximo à viagem última, dedica-se, uma vez mais, à sábia brincadeira de transgredir a linguagem, até que, socraticamente, ela seja capaz de disseminar a dúvida, a incerteza, a inexatidão.

ABSTRACT :

The cited essay discusses the main characteristics of José Paulo Paes' poetry and intellectual work, as well as his legacy in the Brazilian literature scene and to carry out the critical analysis of its posthumous book, Socráticas - poemas.

KEY WORDS: "chiste", irony, generation of '45, epigram, Socrates. 


\section{EM TESE}

Belo Horizonte, v. 9, p. I-28I, dez. 2005

\section{REFERÊNCIAS BIBLIOGRÁFICAS}

ANDRADE, Carlos Drummond de. Da fortuna crítica de 0 aluno. In: PAES, José Paulo. O aluno. Ponta Grossa: UEPG, 1997 .

ARRIGUCCI Jr., Davi. Agora é tudo história. In: PAES, José Paulo. Melhores poemas - José Paulo Paes. São Paulo: Global, 1998.

BONVICIN0, Regis. Jornal da Tarde, São Paulo, 26 mai. 2001. Suplemento, disponivel em: <www.jt.estadao.com.br/ suplementos/saba/2001/05/26/saba004.htm>.

BOSI, Alfredo. [Apresentação] In: PAES. Socráticas - poemas. São Paulo: Companhia das Letras, 2001. p. 13.

MENESES, Eduardo Diatay B. De. 0 riso, o lúdico e o cômico. Revista de cultura, São Paulo, ano 68, n. 4, p. 5-16, 1974.

PAES, José Paulo. O aluno. Ponta Grossa: UEPG, 1997. - Prosas seguidas de odes mínimas. São Paulo: Companhia das Letras, 1992.

Letras, 2001. Socráticas - poemas. São Paulo: Companhia das - Transleituras. São Paulo: Ática, 1995. - Quem, eu? Um poeta como outro qualquer. São Paulo: Atual, 1996. - Um poeta como outro qualquer. Ponta Grossa: Editora UEPG, 1996.

- As aventuras de José Paulo Paes. Leia, São Paulo, mar. 1990. Entrevista concedida a Antônio Paulo Klein, p. 31-34.

PAIXÃo, Fernando. 0 "cantinho do Zé". Cult - Revista Brasileira de Literatura, São Paulo, mar. 1999. Dossiê José Paulo Paes, p. 50-53.

PESSANHA, José Américo Motta. Vida e Obra de Sócrates. In: Sócrates. São Paulo: Nova Cultural, 1996. (Coleção Os pensadores, p. 6.) 